\title{
Yin-Yang representation of financial crisis: A Korean perspective
}

\author{
Amee Kim* \\ Christ Church Business School \\ Canterbury Christ Church University \\ North Holmes Road, Canterbury, \\ CT1 1QU, United Kingdom \\ email: amee.kim@canterbury.ac.uk \\ Frederique Jos Vanheusden \\ Department of Engineering, School of Science and Technology \\ Nottingham Trent University, Clifton Campus \\ Clifton Lane, Nottingham, \\ NG11 8NS, United Kingdom \\ email: frederique.vanheusden@ntu.ac.uk
}

\begin{abstract}
*Corresponding author: Amee Kim, Christ Church Business School, Canterbury Christ Church University, North Holmes Road, Canterbury, CT1 1QU, United Kingdom. E-mail: amee.kim@ canterbury.ac.uk. Tel: (+44) (0)1843 609159.
\end{abstract}

\section{Author Biographies}

Dr Amee Kim is a senior lecture in accounting and finance at Canterbury Christ Church University. She received her PhD at School of Management at the University of Leicester. She is interested in the social science of finance and accounting, semiotic analysis in financial markets and sustainability in accounting.

Dr Frederique Vanheusden is a lecturer in biomedical engineering at the Nottingham Trent University. He received his $\mathrm{PhD}$ in Engineering at the University of Leicester. He is interested in digital signal and image processing, with particular interest in medical signal and image processing. 


\section{Yin-Yang representation of financial crisis: A Korean perspective}

\section{Abstract}

Although the concepts of Western-Eastern integration to optimise management strategies are well-established, investigations on the applicability of these concepts in real-life situations are lacking. This study investigates how integration of (Eastern) Yin-Yang principles of seeking balance into Western concepts benefitted Koreans in combatting financial crises repercussions. Through analysis of 519 South Korean economic magazine covers taken over the period 20072012, the study shows the mindset of Korean society during the 2008 financial crisis. The covers provide a balanced interpretation of crisis events as both disastrous and opportunistic. Traditional Yin-Yang values therefore appear to be preserved in Korean management philosophy, even though contemporary Korean business strategies are strongly influenced by Western principles. By comparing these findings with social attitudes during previous crises in Korea, the study provides a real-life example of possible benefits of integrating Eastern and Western philosophy in management strategies. 


\title{
1 Introduction
}

\begin{abstract}
"Yin-Yang thinking might well find a valuable place alongside western-style formal rationality. Yin-Yang might creatively illuminate processes in social science sensemaking, while formal rationality might provide understanding of demonstrated relations between components that require a sense of process for them to be fully understood." [Redding, (2017), pp. 152-153]

"What is the logic of YinYang? A successful answer ... will lift YinYang from an indigenous philosophy to a formal system of science philosophy... that is complementary to Western metaphysics and dialectics." [Zhang et al., (2016), p. 725]
\end{abstract}

The contemporary rise of Asian influences on global economy and politics continues to proliferate interactions between the $\mathrm{West}^{1}$ and East ${ }^{2}$. In many instances, opposing cultural values or traditions hamper these interactions. Finding appropriate ways to improve fluency in multicultural interactions has led to a vast amount of research on strategies to merge Western and Eastern perspectives in social and entrepreneurial management (Chen and Miller, 2010), business (Liu and Stening, 2016), finance (Kim, 2019), politics (Wu and Bell, 2014) and science (Redding, 2017). An Eastern stream receiving much attention is the ideology of YinYang (Fang, 2012; Li, 2012; Zhang et al., 2016). The Yin-Yang symbol embodies duality, paradox, unity in diversity, change, and harmony (Chen and Miller, 2010; Fang, 2012; Kommonen, 2011; Li, 2012, 2014a, 2014b; Li et al., 2012; Yun, 2013; Zhang, 2009; Zhang et al., 2016). Yin-Yang provides a holistic approach to problem-solving (Chen, 2002; Li, 1998). Rather than following the Western idea of 'either/or', Yin-Yang suggests that opposites coexist within each element of life and are essential for the dynamic transformation of objects (Chen and Miller, 2010; Fang, 2012; Kommonen, 2011; Li, 2012, 2014a, 2014b; Li et al., 2012). As such, Yin-Yang allows explaining the duality of paradoxes as 'opposites-in-unity' (Li, 2014a). By allowing paradoxes, Yin-Yang is considered a more balanced framework for decisionmaking. It allows decision-making based on both logic and intuition, rather than solely logic considered by mainstream Western philosophical frameworks (Burtt, 1953; Li, 2012, 2014b). 
A pitfall when applying East-Asian management strategies is excess attention to the relational perspective between business partners (Chen and Miller, 2011). As such, Chen and Miller (2011, p. 6) argue that managers desiring to be successful in the current global environment need to build on "the best [practices] from both East and West".

To gain a better understanding of Yin-Yang principles and their effects on everyday life in South Korea (afterwards Korea), there is a need to demonstrate these principles and influences in real-life management studies. An interesting approach from a financial and economic perspective is to demonstrate how Yin-Yang was used to represent the financial crisis of 2008 in Korea. Many studies have shown that Yin-Yang values play an important role in everyday Korean life (Ahn, 2009; Cha et al., 2005; Kihl, 1994; Kim and Park, 2003; Kim, 2000, 2001, 2012; Koo, 2009; Kwon, 2011; Lee and Ramsey, 2011; Lie, 2012; Park, 2009). Yet, as a result of the long-living relationship with the USA and other Western countries since the Korean War (1950-1953), Korean businesses evolved towards following Western principles of finance and economics (Kim et al., 1999; Lee, 2003; Warner, 2016; Wright and Kwon, 2006). Over time, a balance has been achieved between these Western strategies whilst maintaining traditional Yin-Yang values (Kim and Park, 2003; Mitu, 2015; Yang and Horak, 2017). This balance between capitalist and Confucian principles has been considered the "force that has given rise to a special kind of capitalism in the Korean society" [Mitu, (2015), p. 32]. It makes Korea an ideal example of how Western and Eastern principles can meet and work in harmony. The 2008 financial crisis is an interesting exemplar to study differences in perception between East and West as its repercussions had global as well as local effects on economy and society. One can therefore investigate the difference in behaviour between Western and Eastern countries towards shared crisis events. Whereas the West generally perceived this period as negative, leading to stronger restrictions on financial management (Knights and McCabe, 2015; 
Loorbach et al., 2016; Tourish and Hargie, 2012), this paper will show that in Korea, the financial crisis was regarded rather as a need to renegotiate financial management strategies due to a temporary imbalance between Yin and Yang perspectives. As with any crisis, Koreans expected that, once an appropriate change in strategy is found, balance between Yin and Yang would be restored. This restoration of balance would mark the end of the crisis. This alternative viewpoint can provide improved strategies on communication and collaboration within a globalised society as "the perception and representation of phenomena ... can give scope for motivating and/or justifying responses." [Loorbach et al., (2016), p. 2].

The aim of this paper is to exemplify the strength Yin-Yang principles have on Korean life using the representation of Yin-Yang in Korean economic magazine covers during the 2008 financial crisis. To achieve this, we quantitatively analysed the representation of the search for balance during crisis events through Yin-Yang using Korean economic magazine front covers. This was achieved through mathematically representing the semiotic interpretation of traditional Yin-Yang values given to colours and vowels in the Korean language (Hangeul: 한글). As such, this paper adds to current literature on by providing means to analyse messages from an Eastern perspective, thereby improving understanding on appropriately implementing Eastern values into Western management strategies, which could improve communication and collaboration in multicultural organisations.

We organised the paper as follows: the first section will introduce the Yin-Yang principles and their importance in Korean culture, society and business structures. The methods section will describe the dataset and the theoretical framework for quantitatively analysing Yin-Yang content on magazine covers. Results will be compared to the behaviour of Koreans during previous crises to provide evidence of the importance of Yin-Yang values in Korean life. It 
will further show how the theoretical framework can be extrapolated to investigate other interactions between East and West and how this can improve collaborations within multicultural organisations.

\section{Yin-Yang and the Korean Financial Crisis}

\subsection{Confucianism and Yin-Yang}

The Yin-Yang symbol originates from Confucianism (Baek, 2012; Fang, 2012; Im, 2007; Kim, 2012; Li, 2006; Nylan, 2008; Shim, 2004; Yun, 2013). For over 2,500 years, Confucianism has been one of the most predominant foundations for philosophy, science, social justice, business, cultural values, and ethics in the East, emphasising on moral and ethical human behaviour in everyday life (Chung, 2016; Chung et al., 2008; Hofstede and Bond, 1988; Kim and Park, 2003; Li, 1998; Little, 2009; Tu, 1996; Yum, 1988). In contrast to contemporary Western culture, which focuses more on defining qualities of materialism and individualism (Ahuvia, 2002; Eckersley, 2005; Triandis and Gelfand, 1998), Confucian philosophy implies that individuals should take their role in a family, community, nation, and nature (Deuchler, 1992; Liu and Stening, 2016). Liu and Stening (2016, p. 824) state that: "Confucius based his philosophy on familial morals, such as filial piety and brotherly love ... and believed that through creating a class of true gentlemen his ideas would eventually be implemented".

Yin-Yang is considered a unique interpretive framework that embraces nature, human beings, and society, and all beings and phenomena have been adapted to this framework (Baek, 2012; Kim, 2012). It places high priority on maintaining harmony in order to achieve prosperity. In terms of Daoism, maintaining harmony is requires flexibility, as it involves continuous, dynamic re-accommodation to the constantly changing flux in the environment (Chen 2001, Chen and Miller 2011). The interpretation of and adaptation towards the continuous interplay 
between Yin and Yang aspects generates balance and harmony in life (Chen et al., 2010; Kui, 2011). In this sense, the East has tried to deal with uncertainties and complexities in life by embracing them, whereas the West has tried to reduce or substitute them [Li, (2016), p. 49].

Yin and Yang symbolise this flexibility and openness: the Yin-Yang symbol shows no absolute borderline between Yin and Yang (Chen and Miller, 2010; Fang and Faure, 2011; Kommonen, 2011). Instead, a dot of Yin exists in Yang, and a dot of Yang exists in Yin. The curvy line in the symbol further implies that there is no absolute distinction. Rather, Yin-Yang principles embody duality, paradox, unity in diversity, change, and harmony (Chen, 2002; Li, 2014a). Natural dualities are good examples of this vision. Every object, experience or thought-process has Yin and Yang aspects as e.g. light (Yang) cannot exist without darkness (Yin), and vice versa.

Yin-Yang also influences identity. In China, for example, an attempt to ask people whether they are 'feminine' or 'masculine', 'implicit' or 'explicit', 'high-context' or 'low-context' could make them confused, because they think more according to concepts of 'both/and', rather than 'either/or' (Chen, 2001, 2002; Fang, 2003, 2005; Fletcher and Fang, 2006). The duality is also used to signify the relationship of a human with his/her self, with others or his/her harmonic position with nature (Raphals, 1998).

The principle of interplay between opposites in Yin-Yang contrasts to main Western principles, which rely mostly on logic and causal behaviour (Burtt, 1953). Recent studies looking into conceptualising Yin and Yang showed that it has the potential to react against the drawbacks of the logical frameworks in Western countries ( $\mathrm{Li}, 1998,2016)$, for example by framing ambiguity so as to ambiguity as a dimension of uncertainty [Li, (2016), p.46]. In this sense, Yin-Yang principles could provide new insights in intercultural collaborations and 
management of business and economy (Li, 2016; Liu and Stening, 2016; Redding, 2017), although appropriate ways of blending eastern and western philosophies [Redding, (2017) p. 153] need to be further explored.

\subsection{Confucianism and Yin-Yang in business}

Although there are many distinctions between the West and the East, Asian countries have shaped their economic strategies strongly towards Western-centred economic principles, focusing mostly on economic performance (Lee and McNulty, 2003; Warner, 2016; Yoon et al., 2017). Business decisions are largely drawn on cost and benefit, such that an appropriate decision-making process results in maximisation of shareholders' well-being (Lee and McNulty, 2003). The need for economic growth in a rapidly globalising world forced Eastern countries to directly apply the advanced Western-oriented market principles, such as reduced government control -and therefore governmental protection- and free market competition (Deshpandé et al., 2004). As these principles strongly contrast Eastern thinking, adaptation to and acceptance of these values led to conflicts (Fletcher and Fang, 2006; Horak and Klein, 2016; Yang and Horak, 2017). This was especially the case in Korea, where Confucianism has influenced society since the Choseon dynasty in such a manner that many Korean are proud about their Confucian traditions and regard them as unique Korean values [Chung, (2016), p.632]. For example, implementation of Western management strategies shifted business partnerships towards formal organisation, thereby overlooking the importance of informal organisations [Yang and Horak, (2017), p. 3]. Conflicts ultimately resulted in crises such as the 1997 Asian financial crisis (Koo and Kiser, 2001). Western management styles therefore had to be modified to fit within the 'paternalistic' and 'communal culture' of Korea [Yoon et al., (2017), p. 188]. It is through a balanced adaptation of Western values into Eastern traditions 
(or, in other words, the search of harmony between contradictory elements) that Korea's contemporary economic growth could be achieved (Kim et al., 2007).

Before the era of a capitalist economy, Eastern business activities were human-centred, prioritising individuals' attitudes to reach harmonious relationships between human beings and nature (Burtt, 1953; Chen et al., 2010; Yu and Xu, 2009). In contrast with Western countries, Eastern thoughts associated profitable or productive business relationships much more with friendships. Choosing business partners can often be based on Confucian principles. For example, the five 'eternal virtues' [Liu and Stening, (2016), p. 824] can be linked to five elements: wood, earth, fire, metal and water. When a person with a 'wood'-centred nature (i.e. a person who likes to be in control and be busy) starts a business, it is better for him/her to have a partnership with a fire (sociable) or water (flexible) personality, rather than an earth (altruistic) or metal (self-contained) personality (Lee and McNulty, 2003).

In Korea, friendliness between business partners within and between organisations still forms an important perspective for operating a business (Yeo et al., 2017). It provides particular obligations with regards to returning favours between partners (Chia, 2003), namely that "interpersonal justice causes the members of an organisation to expect to be rewarded in the future" [Yeo et al., 2017, p.2]. This attitude can however lead to corruption through corporates providing favours to receive favours in the future. An example of this pitfall is the latest scandal surrounding Korean ex-president Park Geun-Hye, whose aide Choi Soon-Sil was accused of receiving briberies from Korean multinational companies in return for political favours (Lee, 2017).

Korean business information also tends to use more indirect and symbolic expressions rather than the more direct approach of Western culture (Lee and McNulty, 2003). This indirectness 
can be found in general in Korean society, with people for example saying "It is quite warm in this office" to indicate that they would like a window to be opened. In business, "no deal" will normally not be expressed as such, but more likely as "deal difficult to comply with".

The Yin-Yang duality can also be related with the dynamic movements of economic development. Economic acts arise from continuously transforming movements amongst market principles (Schumpeter, 2009), which continuously influence current Korean (and furthermore worldwide) economy. Koreans understand that economic conditions are changeable, rather than static. The duality of Yin-Yang can be extended into more complicated framework with endless movements that can include four (Yin in Yin, Yin in Yang, Yang in Yin and Yang in Yang), or more elements to explain economic environments ( $\mathrm{Yu}$ and $\mathrm{Xu}$, 2009). Unlike a rather 'hard' Western description of financial crisis, Koreans see crisis periods as inevitable and periods of hardship which still include opportunities and will be followed by profitable times once balance between Yin and Yang is restored. The main aim during crisis is therefore to find ways of restoring Yin-Yang balance. In this sense, Korean people demand businesses and governmental institutions to take balanced decisions and investigate the reasons behind fortunes and misfortunes. One example is the 2008 candlelight manifestation, in which Koreans protested against the decision of the government to lift the ban on import of American beef (Lee, 2017). Korean people were concerned this lift was politically and economically driven and neglected public health concerns [Lee, (2017), p. 194-195]. More recently, manifestations to find the reasons behind the Sewol ferry incident, the potential lack of effort for saving people on board that ferry (Heo and Park, 2017; Huh et al., 2017), and following "mistrust, paranoia, and anger about the government" [Huh et al., (2017), p. 232] show the Korean community will not tolerate unbalanced decision-making and is committed to returning balance in life through understanding reasons behind crises. 


\subsection{Extracting Yin-Yang features from Hangeul vowels and colours}

Hangeul characters are regarded as the only characters embedding philosophical elements, as the character system was developed based on visual expressions of phonological qualities (Baek, 2012; Kim, 2012).The shape of Hangeul vowel characters originates from Yin-Yang duality (Baek, 2012; Brown and Yeon, 2015; Cho, 2006; Hong, 1990; Kim, 2012; Larsen and Heinz, 2012; Lee, 1984). Figure 1 shows how Yin-Yang is symbolised in vowels using three features (Cho, 2006; Daniels and Bright, 1996; Kim-Renaud, 1997; Kim, 1977).:

- a horizontal line representing the Earth (the essence of Yin);

- a dot (or circle) representing Heaven (the essence of Yang); and

- a vertical line representing a standing Human, (the neutral mediator between Heaven and Earth.

Figure 1 about here

Table 1 further demonstrates that the direction of the short line of a Hangeul vowel determines if a vowel symbolises Yin, Yang or neutrality. Vowels can thus be interpreted as follows (KimRenaud, 1997):

- Yin vowels: a short horizontal line to the left of a vertical long line or a short vertical line below a horizontal long line.

- Yang vowels: a short horizontal line to the right of a long vertical line or a short vertical line above a long horizontal line. 
The bottom row shows double-vowels or combined vowels. Valid combinations can only consist of two Yang vowels, two Yang vowels or a Yin-Yang intermediate vowel combined with either a Yin or a Yang vowel. It is not possible to combine a Yang with a Yin vowel (Cho, 2006; Kim-Renaud, 1997; Kim, 1977).

Table 1 about here

As for the colour schemes, previous research has shown how traditional Korean culture associates colours with Yin-Yang symbolism (Kim, 1985, 2010; Lee and Kim, 2007; Lee et al., 2012). Colours also correlate with the five elements (fire, wood, water, earth and metal), and therefore the five Confucian values (Kim, 2010; Shin et al., 2012). Based on these data, the current study relates Yin-Yang symbolism to colours as follows (Kim, 2019; Kommonen, 2011):

- Yang colours: red, green and orange

- Yin colours: blue, purple, black, grey and white

- Neutral colours: yellow and brown

Based on the suggested framework on interpretation of colours and Hangeul vowels, it becomes possible to quantify how strongly traditional Yin-Yang values are incorporated in magazine front covers. This quantification can then be applied to a logic framework (such as BDL) for assessing how strongly Yin-Yang values modulate representation of the 2008 financial crisis in economic magazines, as well as how this representation might influence readers' perspectives towards this crisis. 


\section{Materials and Methods}

\subsection{Dataset}

Front covers from Korean economic magazines were collected over the period 2007-2012 and included samples from: Daily Economy, Plus Economy, Next Economy, HK Business, Economy Insight, MK Economy, and MoneyWeek. All magazines communicate economic and financial news from a Korean perspective.

A total of 745 front covers were collected. Each cover was scanned for the following features in order to be quantify its Yin-Yang contents:

- Headline written in Korean to allow quantification of vowel Yin-Yang characteristics.

- A cover headline consisting at least partially of native Korean words with a minimum of 2 Hangeul vowels. Vowels of non-native Korean words (e.g. Koreanised English) and (company) names were not included in the final analysis.

- Well-defined background colours. In case the cover consisted of a picture/photo, the most profound colour of the picture was considered the background colour (e.g. blue for a picture of the Niagara waterfalls). Covers with multicoloured backgrounds were excluded.

These inclusion criteria led to a total of 519 covers available for further analysis.

\subsection{Quantification of magazine front covers}

A potential way to quantify Yin-Yang symbolism is to represent Yin-Yang frameworks into purely logic-based frameworks. A logic-based Yin-Yang framework was recently developed by (Zhang et al., 2016). This framework is based on bipolar dynamic logic (BDL), which can be considered a "formal generalization of Boolean logic from static bivalent truth domain to dynamic equilibrium domain" [Zhang et al, (2016), p.726], thereby allowing a purely scientific 
approach to the holistic and dualistic characteristics of Yin-Yang. Instead of the classic Boolean operators ( 0 and 1$)$, BDL separates operators into 2 poles which can be positive $(+1)$, neutral (0) or negative (-1). Combining 2 poles into one element leads to 4 basic elements which Zhang et al (2016) describe as a negative pole true/positive pole false unbalanced state (or $\{-1,0\})$, a negative pole false/positive pole true unbalanced state $(\{0,1\})$ a bipolar true or equilibrium $(\{-1,1\})$ and a bipolar false or non-existence $\{0,0\}$. These basic elements can be combined to create complex logic sentences (Zhang et al., 2016).

Table 2 provides an overview of the data collected per year. Each cover was analysed for its Yin-Yang content based on three features: background (or most profound) colour (BC), headline text colour (HC) and headline vowel Yin-Yang characteristics (HV, based on vowels of Korean native words only).

Insert Table 2 about here

The quantitative codes ' -1 ', ' 0 ' and ' +1 ' were assigned to each of the parameters as follows:

- BC: Yin (-1), Yang (+1) or Yin-Yang neutral (0)

- HC: Yin (-1), Yang (+1) or neutral (0), and

- HV: Individual vowel characteristic were given a Yin (-1), Yang (+1) or neutral (0) value. After this, the sum of all vowels was taken to represent the balanced Yin-Yang content. HV sums were compared with the meaning of the entire headline to determine how well HV reflected the mood of the headline. 
This quantification can be considered a simplification of the BDL framework for evaluating Yin-Yang content. A value of -1 (Yin) could be considered equal to a negative pole true/positive pole false unbalanced state, a value of +1 (Yang) to a negative pole false/positive pole true unbalanced state and a value of 0 (intermediate) to a bipolar true or equilibrium. A bipolar false or non-existence could be considered for headlines not containing Korean vowels (e.g. English or Chinese characters) as the rules for Yin-Yang content in these characters are undefined (Zhang, 2009).

The tendency of parameters to reflect Yin, Yang or neutral perspectives on financial news was assessed by counting the number of magazines using a Yin, Yang or neutral parameter. The frequency of symbolising Yin, Yang and neutral values were compared for each parameter, as well as the sum over all parameters (results ranging from -3 to 3 ) for each year and over the entire 2007-2012 period. Similarities in fluctuations between Yin and Yang symbolism amongst parameters was assessed through cross-correlation. Similarly, cross-correlation between individual parameters and the sum was evaluated to determine if any of the parameters contributed more strongly to the behaviour of the sum. All data analysis was performed in MATLAB (version R2018a, The MathWorks, Natick, USA)

Lastly, we used a Fast Fourier Transform (FFT) to determine if changes from Yin to Yang and back behaved periodically in the data. For this purpose, parameter data were resampled to obtain a periodic distribution equal to one sample per day. In case more than one magazine cover was published on a specific day, the mean value for individual parameters over the magazine covers was derived. We determined the main periodicity in change between Yinfocused and Yang-focussed media coverage by identifying the frequency with the highest power in the FFT power spectrum. 


\subsection{Identification of Yin-Yang fluctuations with major financial crisis events.}

In order to establish a potential link between fluctuations in Yin-Yang content on the magazine covers and the financial crisis, we related changes in Yin-Yang content to major events in the financial crisis (e.g. the Northern Rock crisis). To determine a trend and avoid effects due to sudden fluctuations, we plotted events on the sum of Yin-Yang features after applying a moving average filter considering magazine samples of 4 weeks.

\subsection{Statistics}

A Friedman test with multiple comparisons was used to determine significant differences between Yin-Yang content frequencies between and within years. Significance of the dominant frequency was analysed by comparing its power to the average power of 40 neighbouring frequencies (20 above and 20 below) using an F-test with 2 and 80 degrees of freedom with Bonferroni correction for multiple (4) tests. We assumed statistical significance at an alpha level of 0.05. Statistical analysis was performed in SPSS Statistics 25 (IBM, Armonk, USA).

\section{Results}

Figures 2 and 3 show examples of the quantitative analysis applied to positive (Yang) and negative (Yin) magazine covers, respectively. In Figure 2, images convey a bright message. In the left image 'Happy workplace', the background colour is Yin-Yang intermediate (0) and text colour and headline vowels are both Yang $(+1)$, making the total score of +2 . In the middle image, 'Revolution of the Second Place', the headline colour and the headline vowels are both Yang (and therefore coded +1 ), but the background colour is Yin (and therefore coded -1 ). The overall score sums to +1 . In the right-hand image, 'Kind Loan and Kind Fortune', the background colour is Yin (-1), but the text colour and headline vowels are both Yang (twice $+1)$, totalling +1 . 
Figure 2 about here

On the other hand, in Figure 3, three cover images represent disastrous crisis. In the left image ('The complicated bomb of irregular employment law'), the background colour, text colour and headline vowels are all Yin. Each of these three factors is therefore coded -1 and the score of the cover is -3 . The middle image ('Whereto is the Korean financial industry heading due to the US financial breakdown?') has a neutral text colour but the background colour and headline text vowels are Yin (total equals -2). On the right image ('How long will the economy be depressed?'), the background colour and headline vowels are Yin, but the headline text colour is neutral. The score over the entire cover is -2 .

Figure 3 about here

\subsection{Distribution of Yin-Yang content}

The distribution of Yin-Yang content for each parameter per year is shown in Figure 4. A correlation coefficient between HV and the meaning of the headline was 0.64 . We observed that BC was strongly Yin-driven for all years. HC and HV were more evenly distributed, with HC being more Yin-driven for years 2007, 2011 and 2012 and more Yang-driven for 2008 till 2010. HV was consistently more Yang-driven. Friedman tests showed that, for each year, the distributions of the 3 parameters were significantly different $(p<0.001)$. The multiple comparisons showed that $\mathrm{BC}$ was always significantly different from $\mathrm{HV}$, and significantly 
different from HC for all years except 2007. HC and HV were significantly different for 2012 only $(\mathrm{p}=0.04)$. The distribution between each of the parameters over the total period also appeared significantly different (Figure 4(d), p<0.001).

Figure 4 about here

\subsection{Parameter correlations and periodicity}

Table 3 shows the correlation coefficients between the three parameters, and each parameter with the sum over all parameters. Correlations between parameters were weak, with the strongest correlation existing between HC and HV (-0.097). Correlations between the sum and parameters showed the strongest correlation between the sum and HV (0.617), and the weakest correlation between the sum and BC (0.527).

To further analyse the periodicity of change between Yin and Yang content for each parameter data were analysed in the frequency-domain after resampling to one publication per day. Results showed a fundamental period of 81.04 days for BC, 41.28 days for $\mathrm{HC}, 84.15$ days for $\mathrm{HV}$ and 37.08 days for the sum. A comparison of spectral power at frequencies related to these periods with the average power of 40 neighbouring frequencies (20 above and 20 below) showed only the power of the fundamental period for BC was significantly stronger than its neighbouring frequencies $(\mathrm{p}=0.0024$, Bonferroni correction). This indicates a well-defined periodicity existed only for the $\mathrm{BC}$ parameter.

Table 3 about here 


\subsection{Yin-Yang content in relation with financial crisis events}

The behaviour of the sum of Yin-Yang content over the full crisis period is given in Figure 5. The figure further indicates major events occurring during the crisis period. Overall, the sum of Yin-Yang content appears to fluctuate around 0, with positive peaks and negative troughs. There does not seem to be a direct relationship between troughs and negative events, nor between peaks and positive events.

Figure 5 about here

\section{Discussion}

Across the wide and indigenous discipline of management studies, more attention is being paid to the concept of Yin-Yang to determine how it can contribute to merging Eastern and Western management strategies, thereby creating hybrid strategies that improve current standards (Fletcher and Fang, 2006; Li, 2014a). It is important, however, to learn how to apply theoretical frameworks of Yin-Yang into real-life situations occurring within a managerial environment. In this work, Yin-Yang duality was applied in order to provide an alternative interpretation of the 2008 financial crisis compared to Western strategies (Brassett and Clarke, 2012; De Cock et al., 2011; Goodhart, 2008; Tourish and Hargie, 2012). The representation of the 2008 financial crisis in South Korean media is one example of implementing Yin-Yang principles in order to search for opportunities during an economically disastrous period. This paper shows, through quantitative analysis, that Yin-Yang values play a major role in representation of crisis 
in South Korea, although the country has found strong inspiration in developing finance and business models, as well as social behaviour, from the West.

\subsection{Importance of Yin-Yang in Korean life}

Several studies have indicated that merging Western management theories with non-Western culture can lead to challenges within societies (Luo and Rui, 2009). According to Leung (2006), culture and economic development influence one another, and Korea's (but also China's, Taiwan's, Hong Kong's and Singapore's) current economic success based on re-interpretation of long-standing values and incorporation of Western theories has induced value changes in the East. Economically, Korea has strongly benefitted from Western-driven management theories and practices, becoming a main player in the international market. Yet in order to achieve this, Korea has been forced to maintain emphasis on finding a balance between conflicting forces created through interaction between Western and Eastern perspectives in its business organisations and, more generally, its society (Kim and Park, 2003). As part of finding this balance in life and within the society, Korean culture puts high priority on establishing harmony based on Confucian principles, especially Yin-Yang perspectives (Baek, 2012; Kim, 2000, 2001, 2012).

In a similar way, research studies have developed theoretical frameworks on how merging YinYang perspective with Western culture could optimise management strategies. There is, however, a lack of tools for evaluating how strongly these philosophical context are embedded in the worlds perception of ordinary eastern communities, making it difficult to determine to what extent Yin-Yang principles benefit these communities, let alone how they could benefit Western society. The aim of the paper was therefore to develop a context-specific quantitative method that measures the abstract concept of Yin-Yang within Korean society. This method 
was applied to the interpretation of economic magazine cover images around the 2008 financial crisis (2007-2012). We believe it is the first time that such a quantitative analysis is performed for assessing the impact of cultural values on the perception of global events.

\subsection{The pattern of Yin-Yang harmony during the 2008 financial crisis}

For every parameter (i.e. BC, HC, and HV), we calculated the frequency of Yin-Yang numerical values on the front covers to determine whether specific patterns in the behaviour of Yin-Yang concepts showed harmony between positive and negative signs during the crisis period, in accordance with the Korean idea about crisis. We also investigated fundamental periods over which parameters covered a full Yin-Yang cycle.

According to Figure 4, BC showed a high frequency of Yin-based values. It therefore seems evident that economic magazine front covers were immersed in communicating disastrous situations, as expected in crisis times. On the other hand, HC and HV correspond more strongly to harmonious interactions of Yin-Yang characteristics, with $\mathrm{HC}$ showing no particular tendency over the years, but HV showing tendency to Yang. One could therefore argue that the headline text is used by the magazine designers to indicate balanced positive and negative sides of the crisis. The $\mathrm{BC}$ distribution could then be interpreted as a reminder to the reader that, although there are positive and negative sides of the crisis, overall the economy remains in a crisis. This principle can be corroborated by analysing the correlation coefficients between the parameters and the sum, which was highest for the HC and HV parameters. The correlations amongst the parameters were weak, indicating that parameters appear to behave independently from one another, and therefore contribute independently to the behaviour of the sum of the entire crisis period. The higher correlation between HV and the sum can infer that the designers are using the vowel Yin-Yang characteristics to drive the cover image to a more balanced (but 
still mostly negative) Yin-Yang content. One could argue that positive vowel structure does not necessarily mean the designers used positive words, as for example the Hangeul word for bad (nappeun: 나븐) contains a Yang-characteristic and neutral vowel. Hangeul also still follows the rules of Yin-Yang harmony (Figure 1), meaning that Yin vowels should not occur with Yang vowels in, e.g. verb conjugations, and specific consonants related to the Five Elements (water, wood, fire, metal and earth) should not be linked with Yin or Yang vowels (Sohn, 2001). Puns and metaphors are also frequently used in Korean language (Han and Ahn, 2004), meaning that positive words might be used in headlines to provide a humoristic (or sarcastic) tone to the message. Moreover, as Korean culture has been influenced by the West, designers might direct their use of colours to target a 'Western' interpretation. One example would be the use of red, originally a Yang-based colour, to indicate danger. Previous work interviewing designers has suggested that selecting colours based on Yin-Yang principles might not be intentional, in the sense that colours are chosen strictly on their Yin-Yang features, but that there is a tendency with the designers to show positive and negative aspects of crisis on the cover images (Kim, 2016). However, designers indicated that their use of particular symbols or signs is based on generalised perceptions of Korean society. These alternative design philosophies explain why the correlation between HV and the meaning of the entire headline can be considered good (0.64), but not excellent.

The periodicity of change between Yin and Yang appeared to be shorter for the HC parameter. This slow periodicity further indicates that $\mathrm{BC}$ and $\mathrm{HV}$ indicate slower trends during financial crisis, while HC shows shorter term changes between Yin and Yang.

Finally, the sum of three factors was used to determine the role of Yin-Yang symbolism in interpreting the seriousness of Korean financial breakdown or recovery. Figure 5 shows 
particular peaks and troughs, especially in the early stages of the crisis (2007-2008). These do not necessarily correspond to positive or negative events indicated on the graph, possibly due to different focus of Korean magazines towards implications of crisis events in the USA and Europe on local economy. Indeed, looking at the headlines of Korean economic magazine during the Lehman Brothers, Northern Rock or other crises indicated in the graph shows that these events are not particularly highlighted. Instead, summaries of events are described in editions weeks or months after the events. This observation can be considered a further indicator of Koreans striving towards balance between positive and negative aspects of the crisis. Rather than immediately perceiving the crisis events as disastrous, an analysis of the benefits and drawbacks of the new situation is performed and a balanced conclusion made based on these interpretations.

\subsection{Korea's perspectives on the 2008 financial crisis parallel with the 1997 financial crisis}

Before the 2008 financial crisis, Korea had gone through a similar economic downfall during the 1997 Asian financial crisis. The 1997 crisis was mainly caused by reduced state-control on companies (Koo and Kiser, 2001). Originally, Korean government had close control over business, with specific regulations about how companies should plan their financial strategies. In the beginning of the 1990s, these regulations were significantly relaxed. This led to company overinvestment and corruptive extension of companies to already saturated industries (Chang et al., 1998). The aggressive business strategies together with uncontrolled liberalisation of capital accounts eventually led to fast increasing foreign debts, business failures or mergers and acquisitions (M\&A) takeovers, and a devaluation of Korean currency. The Korean government needed to cover for a high number of loans or take over debts, leading to the sharp economic downturn inducing the need for International Monetary Fund (IMF) intervention 
(Chang et al., 1998). This induced severe restrictions on and reforms of economic governance (Chang et al., 1998; Koo and Kiser, 2001; Shin and Chang, 2005).

Even though Koreans were experiencing harsh financial issues during the 1997 crisis, a strong belief existed that it was possible to return to a healthy, independent economy (Kee, 2008). Combined with international aid, external regulations for economic restructure and the focus on community as one of the main principles of Confucianism, the time of crisis made almost every Korean participate in the successful financial recovery and swift restoration of stability in the Korean economy (Kee, 2008). Media played an important role in representing people's perspectives on events. To help Korean people keep confidence that the crisis would be solved by their sacrifices, media started, for example, to cover stories of Korean athletes performing well in the USA to symbolise global Korean success, the need for individual self-governance and the duty of individuals to their family and their nation, and showing that positive events continuously occur, even during harsh economic times (Cho, 2008).

\subsection{Implications for multicultural collaboration: message interpretation}

Correctly interpreting messages between parties is of major importance in any form of collaboration. It is well known, however, that individual and socio-cultural factors affect message interpretation (Edwards, 2011). From this perspective, Yin-Yang can be a medium to help understanding Eastern cultural identities in the modern globalised society. Although YinYang is becoming more and more known in the West, its perception remains immature, as it is still often seen as a separation of good and bad, rather than a paradoxical, harmonious coexistence of both (Jenco, 2007). This paper shows how Yin-Yang is used as a means of seeking life balance in a practical example on assessing Korean economic media communication during the 2008 financial crisis. 
Media has the power to influence social behaviour, whilst itself being used to bend perspective of people to social, economic or political changes (Bail, 2012). By quantitatively analysing Yin-Yang features from magazine covers, this paper provides further evidence of the importance of shaping messages by including cultural values when communicating to Korean, communities, as they still value these symbols for representing events. As the harmony between Yin and Yang features on the cover magazines appears to evolve towards a more neutral standpoint during the crisis, it provides insight in the behaviour of Koreans (and how media shapes behaviour of Koreans) to perceiving the financial crisis as an event with benefits and disadvantages, rather than a disaster. In this sense, understanding Yin/Yang-driven philosophical backgrounds can shed light on developing potential future developments in cross-cultural or multi-cultural management theory and practice.

Other studies have also shown the intricate relationship between media and society. A study comparing Korean and American photojournalism showed that Korean photos emphasize groups and main news messages, whereas American photos give more emphasis to individuals and additional features, which is in accordance with cultural values (Kim and Kelly, 2008). Studies on advertisement, further showed that Korean advertisements are more implicit compare to American (Cho et al., 1999). Newspapers in the UK also tend towards local news when comparing Scottish papers to their English counterparts (Rosie et al., 2004). Media also changes in accordance with changes within a society. As such, it is of importance to use English in Korean advertisements if the advertiser desires to show he/she is trendy, as the use of English has been shown to be interpreted as a linguistic expression of modernity (Lee, 2006). On the other hand, media influences society, as studies have shown that media violence can lead to more aggressive behaviour in a society (Anderson and Bushman, 2002), and that people evaluate political messages differently when presented through journalists compared to direct 
communication with politicians (Fogarty and Wolak, 2009). Lastly, advertisements and news features have been shown to be able to influence people's mood based on their contents (Bail, 2012; Bessenoff, 2006).

\subsection{Implications for enhancing organisation and business strategies}

It has been claimed that Chinese banks were not harmed as much as Western banks during the financial crisis thanks to a more abrupt reaction when the crisis erupted and applying a better strategy to manage the crisis ( $\mathrm{Li}$ et al., 2012). The authors claimed that the difference between Western and Eastern business strategies lies in Eastern businesses consistently make small modifications to maintain the balance between Yin and Yang, whereas Western businesses tend to review and modify their strategies irregularly, but more drastically.

As discussed earlier, Korean businesses also follow to some extent traditional values in making decisions on collaborations (Lee and McNulty, 2003). By providing a real-life analysis of the incorporation of these cultural values in economic news conveyance, this paper provides Western scholars and managers a practical example of how a balanced implementation of Eastern perspectives and practices can provide means for business communication and (crisis) management strategies. Likewise, the paper encourages the Eastern scholars and managers to understand their management practices are, consciously and unconsciously, influenced by traditional values. As such, they can be more responsive towards the issues, desires and practices involved in communicating with Western partners, which can be important in the context of global management contexts. Previous studies have indeed shown that investigating transformations within an organisation based on Yin-Yang principles could lead to an improved understanding of possible effects of future re-organisations within companies (Hatch et al., 2015). 


\section{Conclusion}

This study provides a tool for quantitatively analysing Yin-Yang symbolism in communication based on Korean economic magazine covers. It provides a unique insight in how balance between optimism and pessimism is achieved in Korean society when conveying crisis events. By applying a quantitative framework for analysing Yin-Yang symbolism, the study presents an algorithm that is compatible with Western semiotic analysis on message conveyance and interpretation, simultaneously allowing an improved interpretation of messages originating from Eastern societies.

This paper contributes to the field of cross-cultural management in that it demonstrates a practical example of how integration of Western and Eastern principles can provide alternative strategies on responding to (crisis) events. Combining results from the current study with historical analysis of contemporary Korean business management allows improved understanding on where Western and Eastern strategies can be merged, and which caveats might occur when exposing a community to these merged strategies.

The study is limited to applying a quantitative framework to the analysis of Yin-Yang symbolism in economic magazines, which communicate news from the specific viewpoint of financial and economic causes and consequences. Although previous work has shown that Korean cover designers explicitly look for balance between positive and negative messages (Kim, 2019), future studies could be directed towards comparing the quantification of YinYang on cover images with interpretation of covers from a cohort of lay people to determine how obvious Yin-Yang symbolism is perceived by the Korean public.

Future studies could be directed towards applying the quantitative Yin-Yang analysis in studies on communication between Western and Eastern communities. Moreover, future case studies 
on merging Eastern and Western management philosophies and strategies are deemed necessary to improve understanding on how, when and to what extent both strategies can be hybridised. 


\section{References}

Adams St Pierre, E. (2016) ‘The long reach of logical positivism/logical empiricism’, in Denzin, N.K. et al (Eds.), Qualitative Inquiry through a Critical Lens, Routledge, New York, pp. 19-30.

Ahn, H.-S. (2009) '음양이론의 상징적 상상력 [Symbolic interpretation of Yin-Yang theory]', 철학과 문화 [Philosophy and Culture], Vol. 18, pp. 107-144.

Ahuvia, A.C. (2002) 'Individualism/collectivism and cultures of happiness: A theoretical conjecture on the relationship between consumption, culture and subjective well-being at the national level', Journal of Happiness Studies, Vol. 3, No. 1, pp. 23-36.

Anderson, C.A. and Bushman, B.J. (2002) 'The effects of media violence on society', Science, Vol. 295, No. 5564, pp. 2377-2379.

Baek, D.-H. (2012) '융합성의 관점에서 본 훈민정음의 창제 원리 [Principle of Hunmin Jeong-Eum in terms of convergence]', 어문론총 [Linguistics], Vol. 57, pp. 115-156.

Bail, C.A. (2012) 'The fringe effect civil society organizations and the evolution of media discourse about Islam since the September 11th attacks', American Sociological Review, Vol. 77, No. 6, pp. 855-879.

Bessenoff, G.R. (2006) 'Can the media affect us? Social comparison, self-discrepancy, and the thin ideal', Psychology of Women Quarterly, Vol. 30, No. 3, pp. 239-251.

Brassett, J. and Clarke, C. (2012) 'Performing the sub-prime crisis: Trauma and the financial event', International Political Sociology, Vol. 6, No. 1, pp. 4-20. 
Brown, L. and Yeon, J. (Eds.), (2015) The handbook of Korean linguistics, John Wiley \& Sons, Chichester.

Burtt, E.A. (1953) 'Intuition in eastern and western philosophy', Philosophy East and West, Vol. 2, No. 4, pp. 283-291.

Cha, H., Oshlyansky, L. and Cairns, P.A. (2005) 'Mobile Phone Preferences and Values: the UK vs. Korea', in IWIPS 2005: Proceedings of the Seventh International Workshop on Internationalisation of Products and Systems, Interaction Design Foundation, Amsterdam, The Netherlands, pp. 29-41.

Chang, H.-J., Park, H.-J. and Yoo, C.G. (1998) 'Interpreting the Korean crisis: financial liberalisation, industrial policy and corporate governance', Cambridge Journal of Economics, Vol. 22, No. 6, pp. 735-746.

Chen, H.-J., Tsai, Y.-H., Chang, S.-H. and Lin, K.-H. (2010) 'Bridging the systematic thinking gap between east and west: An insight into the Yin-Yang-Based system theory', Systemic Practice and Action Research, Vol. 23, No. 2, pp. 173-189.

Chen, M.-J. (2001) Inside Chinese business: A guide for managers worldwide, $1^{\text {st }}$ edition, Harvard Business Press, Boston.

Chen, M.-J. (2002) 'Transcending paradox: The Chinese "middle way" perspective', Asia Pacific Journal of Management, Vol. 19, Nos. 2-3, pp. 179-199.

Chen, M.-J. and Miller, D. (2010) 'West meets East: Toward an ambicultural approach to management', The Academy of Management Perspectives, Vol. 24, No. 4, pp. 17-24. 
Chen, M.-J. and Miller, D. (2011) 'The relational perspective as a business mindset: Managerial implications for East and West', The Academy of Management Perspectives, Vol. 25, No. 3, pp. 6-18.

Chia, R. (2003) 'From knowledge-creation to the perfecting of action: Tao, Basho and pure experience as the ultimate ground of knowing', Human Relations, Vol. 56, No. 8, pp. 953 981.

Cho, B., Kwon, U., Gentry, J.W., Jun, S. and Kropp, F. (1999) 'Cultural values reflected in theme and execution: A comparative study of US and Korean television commercials', Journal of Advertising, Vol. 28, No. 4, pp. 59-73.

Cho, Y. (2008) 'The national crisis and de/reconstructing nationalism in South Korea during the IMF intervention', Inter-Asia Cultural Studies, Vol. 9, No. 1, pp. 82-96.

Cho, Y.Y. (2006) 'Sound symbolism in Korean', in Sohn, H.-M. (Ed.), Korean Language in Culture and Society, University of Hawaii Press, Honolulu, pp. 64-73.

Chung, K.Y., Eichenseher, J.W. and Taniguchi, T. (2008) 'Ethical perceptions of business students: Differences between East Asia and the USA and among "Confucian" cultures', Journal of Business Ethics, Vol. 79, No. 1, pp. 121-132.

Chung, S.-Y. (2016) 'To have or to be? Narrating Confucian value in contemporary Korea', International Communication of Chinese Culture, Vol. 3, No. 4, pp. 631-643.

Daniels, P.T. and Bright, W. (Eds.), (1996) The world's writing systems, Oxford University Press, Oxford.

De Cock, C., Baker, M. and Volkmann, C. (2011) 'Financial phantasmagoria: corporate imagework in times of crisis', Organization, Vol. 18, No. 2, pp. 153-172. 
Deshpandé, R., Farley, J.U. and Bowman, D. (2004) 'Tigers, dragons, and others: Profiling high performance in Asian firms', Journal of International Marketing, Vol. 12, No. 3, pp. $5-29$.

Deuchler, M. (1992) The Confucian transformation of Korea: A study of society and ideology, $1^{\text {st }}$ edition, Harvard University Asia Center, Cambridge.

Eckersley, R. (2005) 'Is modern Western culture a health hazard?', International Journal of Epidemiology, Vol. 35, No. 2, pp. 252-258.

Edwards, R. (2011) 'Listening and message interpretation', The International Journal of Listening, Vol. 25, Nos. 1-2, pp. 47-65.

Fang, T. (2003) 'A critique of Hofstede's fifth national culture dimension', International Journal of Cross Cultural Management, Vol. 3, No. 3, pp. 347-368.

Fang, T. (2005) 'From "onion" to "ocean": Paradox and change in national cultures', International Studies of Management and Organization, Vol. 35, No. 4, pp. 71-90.

Fang, T. (2012) 'Yin Yang: A new perspective on culture', Management and Organization Review, Vol. 8, No. 1, pp. 25-50.

Fang, T. and Faure, G.O. (2011) 'Chinese communication characteristics: A Yin Yang perspective', International Journal of Intercultural Relations, Vol. 35, No. 3, pp. 320-333.

Fletcher, R. and Fang, T. (2006) 'Assessing the impact of culture on relationship creation and network formation in emerging Asian markets', European Journal of Marketing, Vol. 40, Nos. 3-4, pp. 430-446. 
Fogarty, B.J. and Wolak, J. (2009) 'The effects of media interpretation for citizen evaluations of politicians' messages', American Politics Research, Vol. 37, No. 1, pp. 129-154.

Goodhart, C.A. (2008) 'The background to the 2007 financial crisis', International Economics and Economic Policy, Vol. 4, No. 4, pp. 331-346.

Han, S.-M. and Ahn, G.-B. (2004) 'Theoretical Analysis of the Humor in Korean Traditional Space', Journal of the Korean Institute of Landscape Architecture, Vol. 32, No. 2, pp. 6877.

Hatch, M.J., Schultz, M. and Skov, A.-M. (2015) 'Organizational identity and culture in the context of managed change: Transformation in the Carlsberg Group, 2009-2013', Academy of Management Discoveries, Vol. 1, No. 1, pp.58-90.

Heo, M. and Park, J. (2017) 'Shame and vicarious shame in the news: A case study of the $\begin{array}{llll}\text { Sewol ferry } & \text { disaster', Journalism, }\end{array}$ https://journals.sagepub.com/doi/abs/10.1177/1464884916688928\#articleCitationDownloa dContainer (Accessed 2 January 2019).

Hofstede, G. and Bond, M.H. (1988) 'The Confucius connection: From cultural roots to economic growth', Organizational Dynamics, Vol. 16, No. 4, pp. 5-21.

Hong, K.-S. (1990) 'Subject-to-object raising in Korean', in Dziwirek, K. et al. (Eds.), Grammatical Relations: A cross-theoretical perspective, Center for the Study of Language (CSLI) Publications, Stanford, pp. 215-226.

Horak, S. and Klein, A. (2016), 'Persistence of informal social networks in East Asia: Evidence from South Korea', Asia Pacific Journal of Management, Vol. 33, No. 3, pp. 673-694. 
Huh, H.J., Huh, S., Lee, S.H. and Chae, J.H. (2017) 'Unresolved bereavement and other mental health problems in parents of the Sewol ferry accident after 18 months', Psychiatry Investigation, Vol. 14, No. 3, pp. 231-239.

Im, H.-S. (2007) ‘동양사회사상과 새로운 세계관의 모색 [Oriental social thought and the search for a new world view]', 사회사상과 문화 [Social Thought and Culture], Vol. 16, pp. 15-32.

Jenco, L. (2007) 'A political theory for them: But not for us? Western theorists interpret the Chinese tradition', The Review of Politics, Vol. 69, No. 22, pp. 273-285.

Kee, T.S. (2008) 'Influences of Confucianism on Korean corporate culture', Asian Profile, Vol. 36, No. 1, pp. 1-15.

Kihl, Y.W. (1994) 'The legacy of Confucian culture and South Korean politics and economics', Korea Journal, Vol. 34, No. 3, pp. 37-53.

Kim, A. (2016) '(Re)constructing self-identity during turbulent times of rapid social and economic change: a study of Korean financial crisis perspectives'. Paper Presented at the 30th British Academy of Management Annual Conference. 6-8 September 2016. Newcastle, United Kingdom.

Kim, A. (2019) 'Symbolic representations of financial events in the Korean media', Qualitative Research in Financial Markets, in press.

Kim, A.E. and Park, G. (2003) 'Nationalism, Confucianism, work ethic and industrialization in South Korea', Journal of Contemporary Asia, Vol. 33, No. 1, pp. 37-49. 
Kim, A.I. (1985) 'Korean color terms: An aspect of semantic fields and related phenomena', Anthropological Linguistics, Vol. 27, No. 4, pp. 425-436.

Kim, H.-S. (2000) ‘음양적 사유와 인과적 사유 [Yin-Yang and causal reasons]', 철학적분석 [Philosophical analysis], Vol. 4, No. 1, pp. 52-77.

Kim, J.Y. (2010) 'Color characteristics of costumes for Korean folk festivals and color consciousness of Koreans', Color Research \& Application, Vol. 35, No. 6, pp. 443-453.

Kim, K.-D. et al. (Eds.), (2007) East meets West: civilizational encounters and the spirit of capitalism in East Asia, Brill, Leiden.

Kim, K.-O. (1977) 'Sound symbolism in Korean', Journal of Linguistics, Vol. 13, No. 1, pp. $67-75$.

Kim, M.-T. (2012) ‘훈민정음의 제자원리와 역학사상: 음양오행론과 삼재론을 중심으로 [The Principle and Epistemological Thought of Hunmin Jung-Eum: Focus on Yin-Yang and the Three Kingdoms]', 철학사상 [Philosophical Thought], Vol. 45, pp. 55-94.

Kim, N.-H., Sohn, D.-W. and Wall Jr., J.A. (1999) 'Korean leaders (and subordinates) conflict management', International Journal of Conflict Management, Vol. 10, No. 2, pp. 130-153.

Kim, Y.-S. (2001) '서양 이분법과 동양 음양법의 극복 [Overcoming Western Dichotomy and Oriental Yin-Yang Law]', 사회사상과 문화 [Social Thought and Culture], Vol. 4, pp. $37-80$. 
Kim, Y.S. and Kelly, J.D. (2008) 'A matter of culture: A comparative study of photojournalism in American and Korean newspapers', International Communication Gazette, Vol. 70, No. 2, pp. 155-173.

Kim-Renaud, Y.-K. (Ed.), (1997) The Korean alphabet: Its history and structure, University of Hawaii Press, Honolulu.

King, R. (1996) 'Korean Writing', in Daniels, P.T. et al. (Eds.), The world's writing systems, Oxford University Press, Oxford, pp. 218-225.

Knights, D. and McCabe, D. (2015) “"Masters of the Universe”: Demystifying leadership in the context of the 2008 global financial crisis', British Journal of Management, Vol. 26, No. 2, pp. 197-210.

Kommonen, K. (2011) 'Narratives on Chinese colour culture in business contexts: The Yin Yang Wu Xing of Chinese values', Cross Cultural Management, Vol. 18, No. 3, pp. 366383.

Koo, J. and Kiser, S.L. (2001) 'Recovery from a financial crisis: The case of South Korea', Economic and Financial Review, Vol.4, No. 4, pp. 24-36.

Koo, Y.-S. (2009) '음양오행설의 언어이론 가능성 모색 [The Yin-Yang language theory]', 한민족문화연구 [Korean Culture Research], Vol. 29, pp. 33-60.

Kui, W.K. (2001) 'Hegel's Criticism of Laozi and Its Implications', Philosophy East and West, Vol. 61, No. 1, pp. 56-79.

Kwon, O.Y. (2011) 'Does culture matter for economic development in Korea?', The Journal of East Asian Affairs, Vol. 25, No. 2, pp. 163-182. 
Larsen, D. and Heinz, J. (2012) 'Neutral vowels in sound-symbolic vowel harmony in Korean', Phonology, Vol. 29, No. 3, pp. 433-464.

Lee, H.-C. and McNulty, M.P. (2003) East Asia's Dynamic Development Model and The Republic of Korea's Experiences. [online] World Bank Policy Research Working Paper No. 2987, World Bank Group, Washington. https://papers.ssrn.com/sol3/papers.cfm?abstract_id=636349 (Accessed 2 January 2019)

Lee, J.H. and Kim, Y.-I. (2007) 'Analysis of color symbology from the perspective of cultural semiotics focused on Korean costume colors according to the cultural changes', Color Research \& Application, Vol 32, No. 1, pp. 71-79.

Lee, J.S. (2006) 'Linguistic constructions of modernity: English mixing in Korean television commercials', Language in Society, Vol. 35, No. 1, pp. 59-91.

Lee, K. (2017) 'Looking back at the candlelight protests of 2008, South Korea: Reflection on its multiple implications and lessons', International Journal of Cultural Studies, Vol. 20, No. 2, pp. 193-208.

Lee, K.-M. and Ramsey, S.R. (2011) A history of the Korean language, $1^{\text {st }}$ edition, Cambridge University Press, Cambridge.

Lee, M.S., Sa, J.K. and Chung, K.H. (2012) 'A comparative analysis of the characteristics and images of costume colors in the traditional plays of Korea, China, and Japan', Color Research \& Application, Vol. 37, No. 4, pp. 302-312.

Lee, S.-O. (1987) 'An overview of issues in the vowel system and vowel harmony of Korean', Language Research, Vol. 20, No. 4, pp. 417-451. 
Lee, S.M. (2003) 'South Korea: From the land of morning calm to ICT hotbed', The Academy of Management Perspectives, Vol. 17, No. 2, pp. 7-18.

Leung, K. (2006) 'The rise of East Asia: Implications for research on cultural variations and globalization', Journal of International Management, Vol. 12, No. 2, pp. 235-241.

Li, C. (2006) 'The Confucian ideal of harmony', Philosophy East and West, Vol. 56, No. 4, pp. 583-603.

Li, J., Leung, A.S., Young, M., Xin, Y., Cai, Z. and Huang, J. (2012). 'A yin/yang perspective on the 2008 global financial crisis', British Journal of Management, Vol. 23, No. S1, pp. S119-S125.

Li, P.P. (1998) 'Towards a geocentric framework of organizational form: A holistic, dynamic and paradoxical approach', Organization Studies, Vol. 19, No. 5, pp. 829-861.

Li, P.P. (2012) 'Toward an integrative framework of indigenous research: The geocentric implications of Yin-Yang balance', Asia Pacific Journal of Management, Vol. 29, No. 4, pp. $849-872$.

Li, P.P. (2014a) 'The Unique Value of Yin-Yang Balancing: A Critical Response', Management and Organization Review, Vol. 10, No. 2, pp. 321-332.

Li, P.P. (2014b) 'Toward the geocentric framework of intuition: The Yin-Yang Balancing between the Eastern and Western perspectives on intuition', in Sinclair, M. (Ed.), Handbook of research methods on intuition, Edward Elgar Publishing, London, pp. 28-41.

Li, P.P. (2016) 'Global implications of the indigenous epistemological system from the East: How to apply Yin-Yang balancing to paradox management', Cross Cultural \& Strategic Management, Vol. 23, No. 1, pp. 42-77. 
Lie, J. (2012) 'What is the K in K-pop? South Korean popular music, the culture industry, and national identity', Korea Observer, Vol. 43, No. 3, pp. 339-363.

Little, R. (2009) 'Confucian reconstruction of global economics and finance', Culture Mandala: The Bulletin of the Centre for East-West Cultural and Economic Studies, Vol. 8, No. 2, pp. $62-73$.

Liu, T. and Stening, B.W. (2016) 'The contextualization and de-contextualization of Confucian morality: Making Confucianism relevant to China's contemporary challenges in business ethics', Asia Pacific Journal of Management, Vol. 33, No. 3, pp. 821-841.

Loorbach, D., Avelino, F., Haxeltine, A. Wittmayer, J.M., O’Riordan, T., Weaver, P. and Kemp, R. (2016) 'The economic crisis as a game changer? Exploring the role of social construction in sustainability transitions', Ecology and Society, 21(4), [online] https://www.jstor.org/stable/26270000?seq=1\#metadata_info_tab_contents (Accessed 2 January 2019).

Luo, Y. and Rui, H. (2009) 'An ambidexterity perspective toward multinational enterprises from emerging economies', The Academy of Management Perspectives, Vol. 23, No. 4, pp. 49-70.

Mitu, B. (2015), 'Confucianism and the Contemporary Korean society', Romanian Journal of Sociological Studies, Vol. 16, No. 1, pp. 31-38.

Nisbett, R. (2004) The Geography of Thought: How Asians and Westerners Think Differently... and $w h y, 1^{\text {st }}$ edition, Simon and Schuster, New York.

Nylan, M. (2008) The Five“ Confucian” Classics, $1^{\text {st }}$ edition, Yale University Press, New Haven. 
Park, S. (2009) 'Analysis of characteristics and trends of Web queries submitted to NAVER, a major Korean search engine', Library \& Information Science Research, Vol. 31, No. 2, pp. 126-133.

Raphals, L.A. (1998) Sharing the light: Representations of women and virtue in early China, $1^{\text {st }}$ edition, SUNY Press, Albany.

Redding, G. (2017) 'Components and process in social science explanation: is there a role for Yin-Yang balancing', Cross Cultural \& Strategic Management, Vol. 24, No. 1, pp. 152-166.

Rosie, M.J., MacInnes, J., Petersoo, P., Condor, S. and Kennedy, J. (2004) 'Nation speaking unto nation? Newspapers and national identity in the devolved UK', The Sociological Review, Vol. 52, No. 4, pp. 437-458.

Schumpeter, J.A. (2009) Can Capitalism Survive?: Creative Destruction and the Future of the Global Economy, $3^{\text {rd }}$ Edition, HarperCollins, New York.

Shim, K.-D. (2004) '주역에서 음양의 조화에 관한 연구 [A study on the harmony of Yin and Yang in the protagonist]', 한국여성철학 [Korean Women's Philosophy], Vol. 4, pp. 1-21.

Shin, J.-S., and Chang, H.-J. (2005) 'Economic reform after the financial crisis: a critical assessment of institutional transition and transition costs in South Korea', Review of International Political Economy, Vol. 12, No. 3, pp. 409-433.

Shin, M.J., Westland, S., Moore, E.M. and Cheung, T.L.V. (2012) 'Colour preferences for traditional Korean colours', Journal of the International Colour Association, Vol. 9, pp. 4859. 
Sohn, H.-M. (2001) 'Sound symbolism', in Sohn, H.-M. (Ed.), The Korean Language, Cambridge University Press, Cambridge, pp. 96-102.

Tourish, D. and Hargie, O. (2012) 'Metaphors of failure and the failures of metaphor: A critical study of root metaphors used by bankers in explaining the banking crisis', Organization Studies, Vol. 33, No. 8, pp. 1045-1069.

Triandis, H.C. and Gelfand, M.J. (1998) 'Converging measurement of horizontal and vertical individualism and collectivism', Journal of Personality and Social Psychology, Vol. 74, No. 1, pp. 118-128.

Tu, W.-M. (1996) 'Confucian traditions in East Asian modernity', Bulletin of the American Academy of Arts and Sciences, Vol. 50, No. 2, pp. 12-39.

Warner, M. (Ed.), (2016) The Diffusion of Western Economic Ideas in East Asia, Taylor \& Francis, Didcot.

Wright, C. and Kwon, S.-H. (2006) 'Business crisis and management fashion: Korean companies, restructuring and consulting advice', Asia Pacific Business Review, Vol 12, No. 3, pp. 355-373.

Wu, Y. and Bell, D.A. (2014) 'The Revival of Confucianism in an Age of Globalization: Towards a Critical Confucianism', The Journal of Multicultural Society, Vol. 5, No. 1, pp. 1-21.

Yang, I. and Horak, S. (2017) 'Formal and informal practices in contemporary Korean management', The International Journal of Human Resource Management, [online] https://www.tandfonline.com/doi/abs/10.1080/09585192.2017.1342683 (Accessed 2 January 2019). 
Yeo, K., Wildman, J.L. and Choi, S.B. (2017) 'The Effects of Confucian Values on Interpersonal Trust, Justice, and Information Sharing of Korean Workers: A Multilevel Analysis', Journal of Pacific Rim Psychology, $11 \quad$ [online] https://www.cambridge.org/core/journals/journal-of-pacific-rim-

psychology/article/effects-of-confucian-values-on-interpersonal-trust-justice-andinformation-sharing-of-korean-workers-a-multilevelanalysis/F364BBFFBE302C885F3564B597A77814 (Accessed 2 January 2019).

Yoon, S.W., Shin, J., Kim, S. and Chai, D.S. (2017) 'Effective Leadership and Leadership Development in South Korea: Lessons Learned from Two Large Conglomerates', in Ardichvili, A. et al. (Eds.), Leadership Development in Emerging Market Economies, Palgrave Macmillan US, New York, pp. 187-206.

Yu, W. and Xu, J. (2009) 'Morality and nature: The essential difference between the Dao of Chinese philosophy and metaphysics in Western philosophy', Frontiers of Philosophy in China, Vol. 4, No. 3, pp. 360-369.

Yum, J.O. (1988) 'The impact of Confucianism on interpersonal relationships and communication patterns in East Asia', Communications Monographs, Vol. 55, No. 4, pp. 374-388.

Yun, S.H. (2013) 'An analysis of Confucianism's yin-yang harmony with nature and the traditional oppression of women: Implications for social work practice', Journal of Social Work, Vol. 13, No. 6, pp. 582-598.

Zhang, W.-R. (2009), 'YinYang Bipolar Dynamic Logic (BDL) and equilibrium-based computational neuroscience' in IJCNN 2009: International Joint Conference on Neural 
Networks, 2009, Institute of Electrical and Electronics Engineers, Atlanta, USA, pp. 35343541.

Zhang, W.-R., Peace, K.E. and Han, H.-J. (2016) 'YinYang bipolar dynamic organizational modeling for equilibrium-based decision analysis: Logical transformation of an indigenous philosophy to a global science', Asia Pacific Journal of Management, Vol. 33, No. 3, pp. 723-766. 


\section{Notes}

${ }^{1}$ For the remainder of this paper, West and western refer to European, including AngloAmerican, traditions of thought following Greco-Roman and Judeo-Christian foundations and their transformations into various modernisms including Western secularism, capitalism, and scientific positivism (Adams St Pierre, 2016; Kim, 2019; Nisbett, 2004).

${ }^{2}$ For the remainder of this paper, East and eastern refer to Asian traditions of thought following Confucian foundations and its transformations such as Buddhism or Taoism (Yum, 1988). 


\section{Tables}

Table 1: Overview of the economic magazine front cover dataset sampled over the period 2007-2012.

\begin{tabular}{c|c|c|c|c|c|c|c} 
& 2007 & 2008 & 2009 & 2010 & 2011 & 2012 & $2007-2012$ \\
\hline $\begin{array}{c}\text { Number of data } \\
\text { samples }\end{array}$ & 100 & 61 & 83 & 134 & 176 & 181 & 735 \\
\hline
\end{tabular}


Table 2: Yin and Yang contents of Korean vowels. The short lines indicate if a vowel is Yin, Yang or intermediate.

\begin{tabular}{|c|c|c|c|}
\hline & Yang & Yin & Yin-Yang Intermediate \\
\hline $\begin{array}{l}\text { Vowels with a long } \\
\text { vertical line }\end{array}$ & $\mathrm{H}, \mathrm{F}, \mathrm{H}, \mathrm{H}$ & $\dashv, \neq, \|, \exists$ & I \\
\hline $\begin{array}{l}\text { Vowels with a long } \\
\text { horizontal line }\end{array}$ & 上,ㄴ & $T, \pi$ & - \\
\hline Double vowels & 나,내,니 & Tㄴ,께,Tा & -1 \\
\hline
\end{tabular}


Table 3: Correlation coefficients between parameters and each parameter with the sum of parameters. P-values are given between parenthesis.

\begin{tabular}{l|cc|c} 
& $\begin{array}{c}\text { Background Colour } \\
(B C)\end{array}$ & $\begin{array}{c}\text { Headline Text } \\
\text { Colour }(K T)\end{array}$ & $\begin{array}{c}\text { Headline Vowel } \\
(K V)\end{array}$ \\
\hline $\begin{array}{l}\text { Background Colour } \\
(B C)\end{array}$ & & & \\
\hline $\begin{array}{l}\text { Headline Text Colour } \\
(\text { KT })\end{array}$ & $-0.08(<0.001)$ & & \\
\hline Headline Vowel $(K V)$ & $-0.06(0.004)$ & $-0.13(p<0.001)$ & \\
\hline Sum & $0.38(<0.001)$ & $0.55(<0.001)$ & $0.61(<0.001)$ \\
\hline
\end{tabular}




\section{Figure captions}

Figure 1: The origin of the Korean language (redrawn from (King, 1996)).

Figure 2: Positive images during the Korean financial crisis. Left: 'The happy workplace.' $(\operatorname{sum}=+2)$. Middle: 'Revolution of the second place.' $(\operatorname{sum}=+1)$. Right: 'Kind loan and kind fortune.' $($ sum $=+1)$.

Figure 3: Negative moments in the Korean financial crisis. Left: 'The complicated bomb of the irregular employment law' (sum = -3). Middle: 'Whereto is the Korean financial industry heading due to the US financial breakdown?' (sum = -2). Right: 'How long will the economy be depressed?' (sum $=-2$ ).

Figure 4: A-C) Distribution of Yin-Yang content in individual years for background colour (A), headline text colour (B) and headline vowel Yin-Yang characteristics (C). Numbers above graphs indicate the number of covers analysed per year. D) Distribution of parameters over the full period between 2007-2012.

Figure 5: Behaviour of Yin-Yang sum over the financial crisis period. Main crisis events are indicated with dotted lines, positive news is indicated with dashed lines. 


\section{Figures}

Figure 1
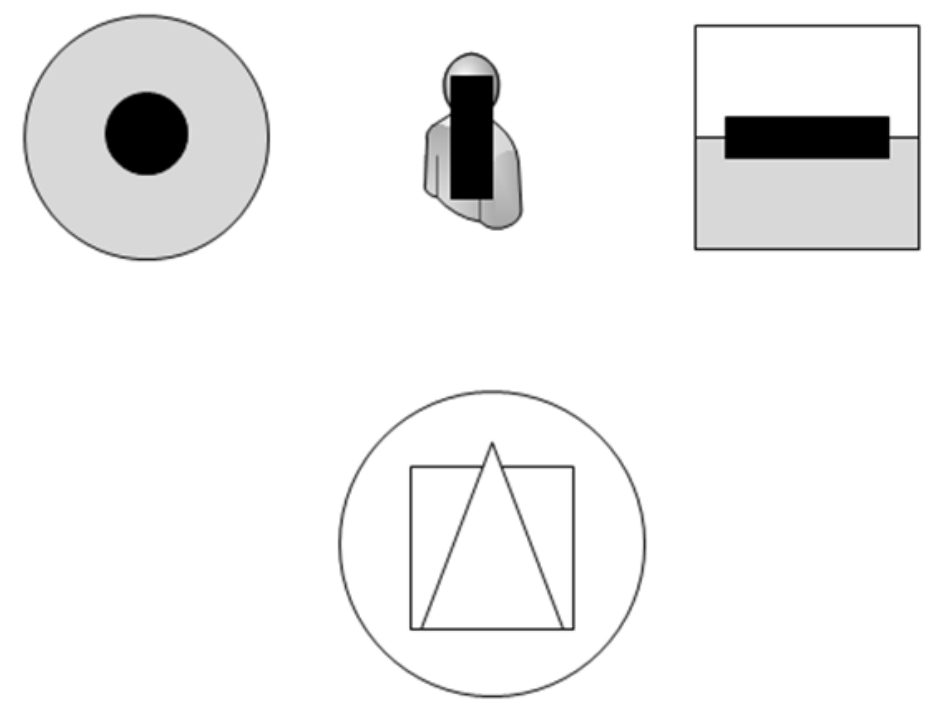
Figure 2
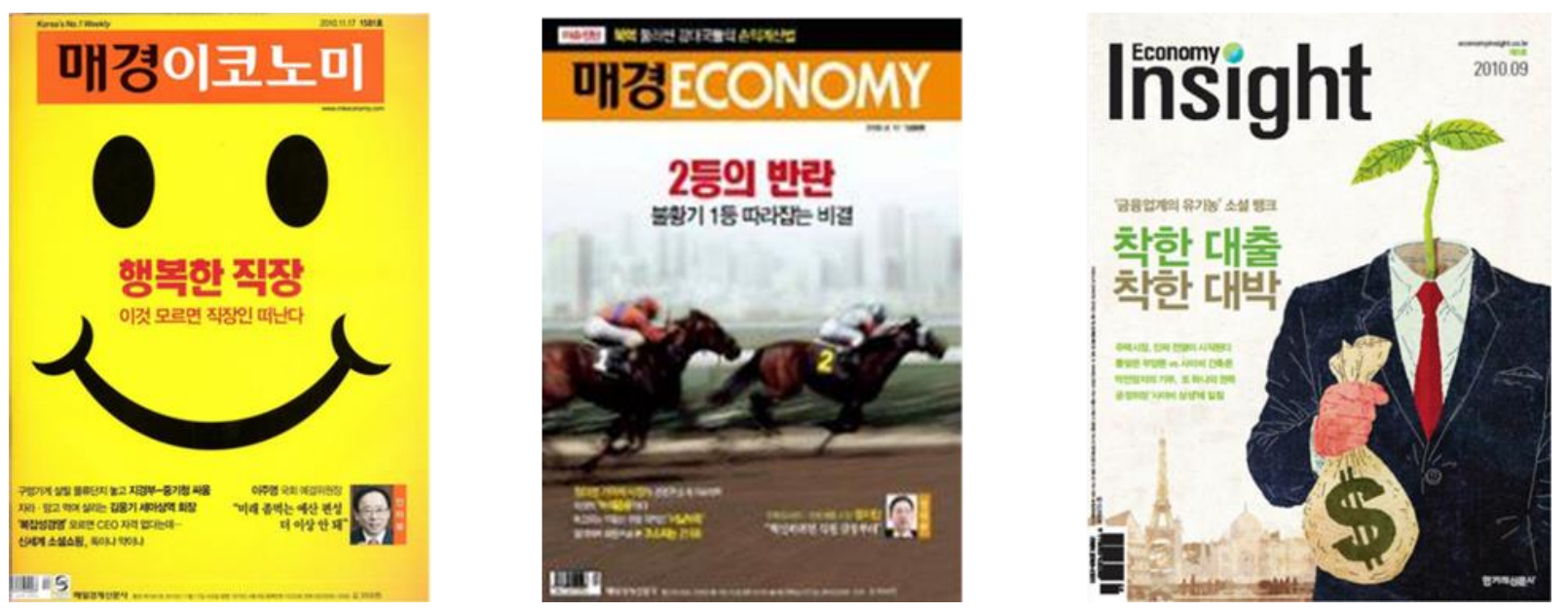
Figure 3
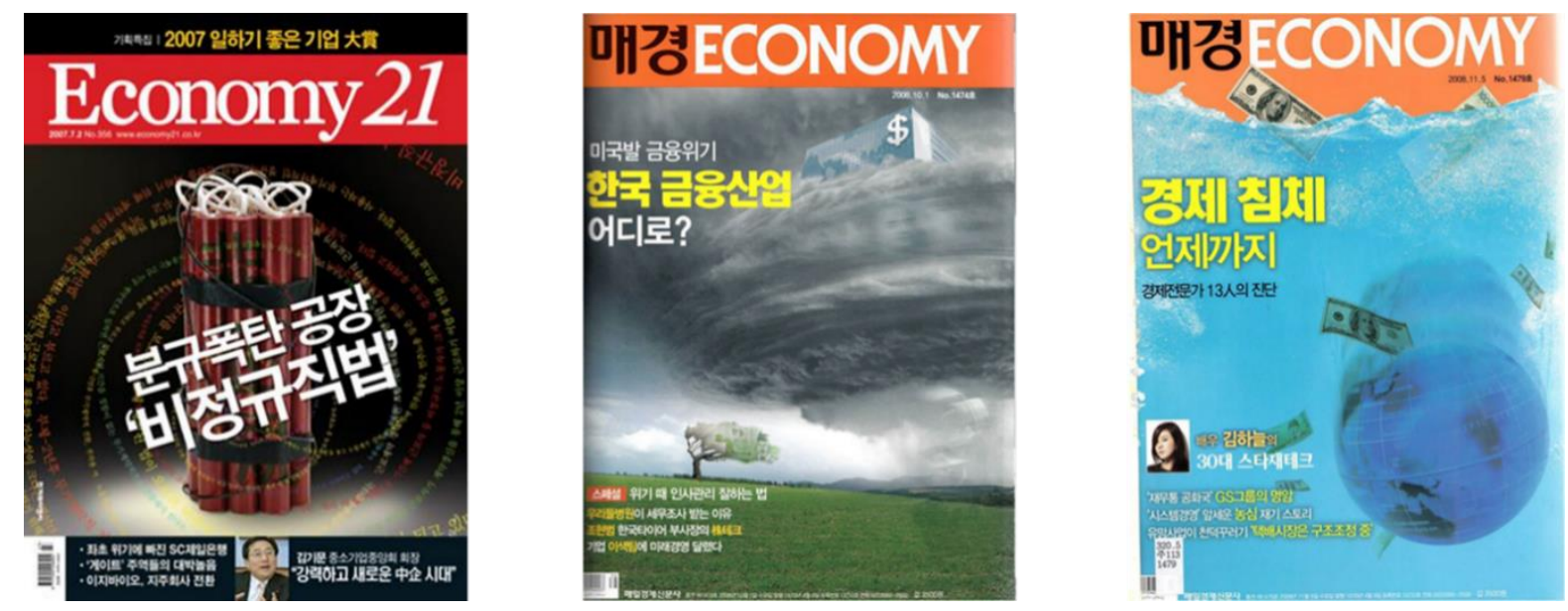
Figure 4
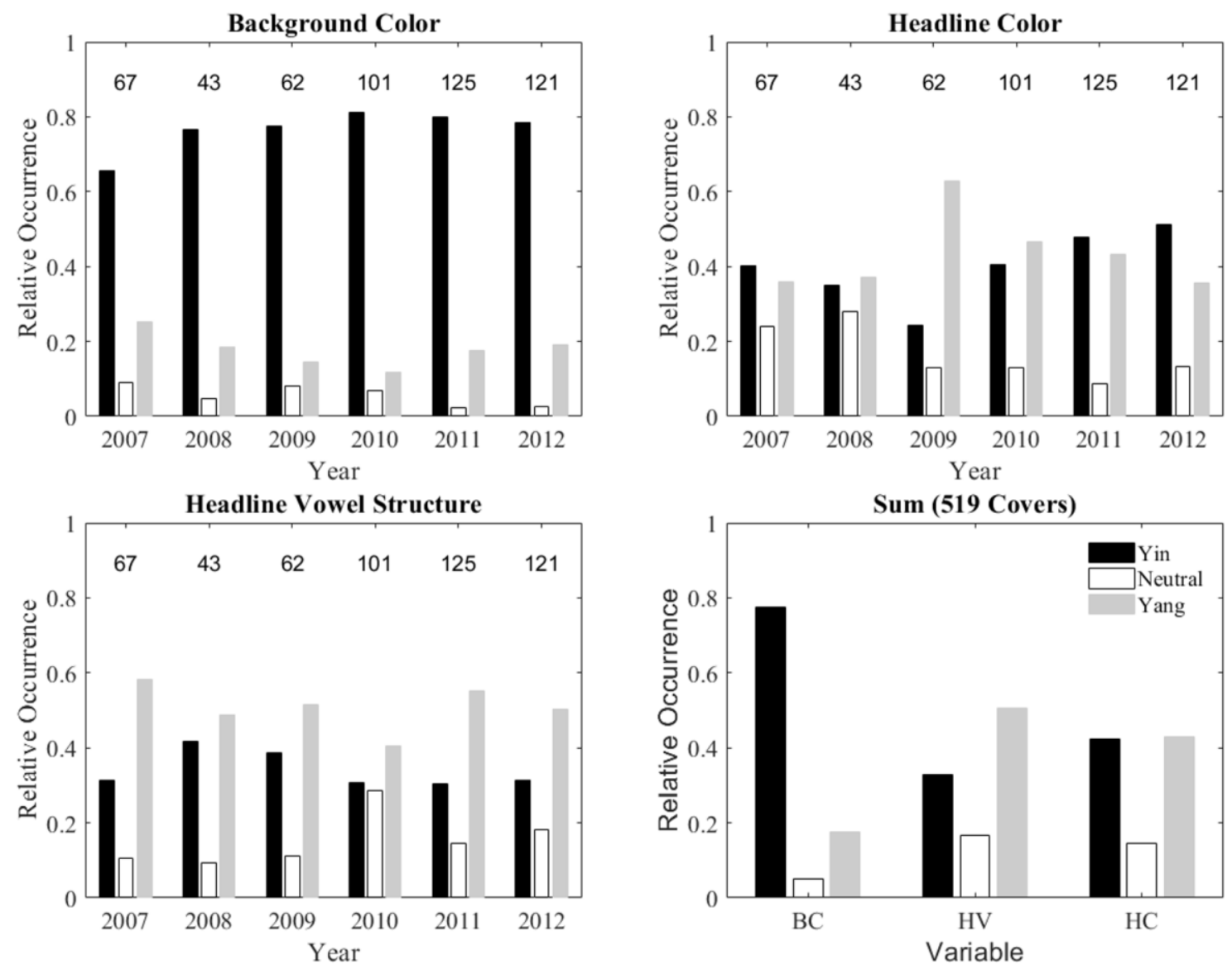
Figure 5

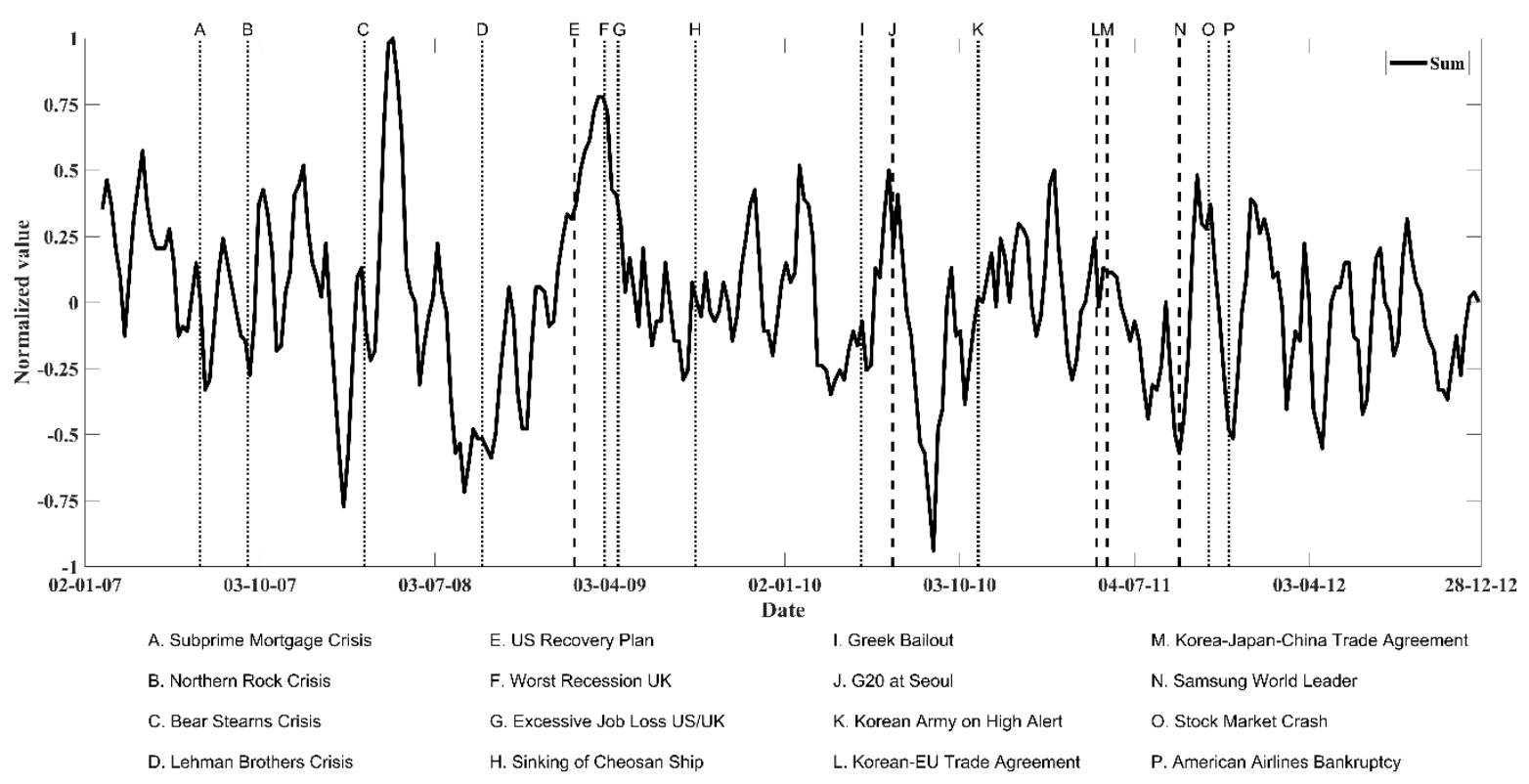




\section{Keywords}

Yin-Yang harmony; Media; South-Korea; Financial crisis; Identity; Economic magazines;

Color interpretation 